\title{
DIAGNOSIS OF ENDOCRINE DISEASE High-yield thyroid fine-needle aspiration cytology: an update focused on ancillary techniques improving its accuracy
}

\author{
M Bongiovanni, P Trimboli 1,2, E D Rossi ${ }^{3}$, G Fadda ${ }^{3}$, A Nobile and L Giovanella ${ }^{2}$ \\ Institute of Pathology, University Hospital, Rue du Bugnon 25, 1011 Lausanne, Switzerland, 'Section of \\ Endocrinology and Diabetology, Ospedale Israelitico, Piazza San Bartolomeo all'Isola 21, 00186 Rome, Italy, \\ ${ }^{2}$ Department of Nuclear Medicine and Thyroid Centre, Oncology Institute of Southern Switzerland, Viale Officina 3, \\ 6500 Bellinzona, Switzerland and ${ }^{3}$ Division of Anatomic Pathology and Histology, Department of Laboratory \\ Medicine, 'Agostino Gemelli' School of Medicine and Hospital, Catholic University, Largo Francesco Vito 1, 00168 \\ Rome, Italy
}

Correspondence should be addressed to M Bongiovanni Email

massimo.bongiovanni@ chuv.ch

\begin{abstract}
Thyroid fine-needle aspiration (FNA) cytology is a fast growing field. One of the most developing areas is represented by molecular tests applied to cytological material. Patients that could benefit the most from these tests are those that have been diagnosed as 'indeterminate' on FNA. They could be better stratified in terms of malignancy risk and thus oriented with more confidence to the appropriate management. Taking in to consideration the need to improve and keep high the yield of thyroid FNA, professionals from various fields (i.e. molecular biologists, endocrinologists, nuclear medicine physicians and radiologists) are refining and fine-tuning their diagnostic instruments. In particular, all these developments aim at increasing the negative predictive value of FNA to improve the selection of patients for diagnostic surgery. These advances involve terminology, the application of next-generation sequencing to thyroid FNA, the use of immunocyto- and histo-chemistry, the development of new sampling techniques and the increasing use of nuclear medicine as well as molecular imaging in the management of patients with a thyroid nodule. Herein, we review the recent advances in thyroid FNA cytology that could be of interest to the 'thyroid-care' community, with particular focus on the indeterminate diagnostic category.
\end{abstract}

\section{Introduction}

Thyroid fine-needle aspiration (FNA) is still among the most commonly performed procedures to evaluate thyroid parenchymal nodules (1). Beside clinically evident and palpable thyroid nodules that are present in up to $7 \%$ of the general population, ultrasonographic evaluation of the neck performed in various clinical settings bring to light up to $70 \%$ of non-palpable and deep-seated nodules $(2,3,4)$. Even if we observe a slight increase in the incidence of thyroid carcinoma, the malignancy rate of thyroid nodules observed in the general population remains low (2-5\% among all thyroid nodules). Thus,
(C) 2016 European Society of Endocrinology Printed in Great Britain the detection of these cancers remains a diagnostic challenge (5). Thyroid FNA under ultrasound (US) guidance remains the most accurate and cost-effective method for the initial evaluation of patients with thyroid nodules and has proven its efficacy as a diagnostic test in several diagnostic categories. The sensitivity and specificity of thyroid FNA are reported to be $68-98 \%$ and $56-100 \%$ respectively. Moreover, thyroid FNA reduces the rate of unnecessary thyroid surgery in patients with benign nodules and allows detection of thyroid cancers requiring a surgical approach (4). 
Despite these diagnostic improvements, thyroid FNA still faces some limitations in the detection of follicular carcinoma (FC) and, to a lesser extent, of the follicular variant (FV) of papillary carcinoma (PC), both neoplasms representing the cytological 'grey zone' (6). Actually, the malignancy rate of $26 \%$ determined after surgery in the follicular neoplasm (FN) diagnostic category contrasts with the excellent results obtained in the other diagnostic categories (7).

New insights emerge from different medical specialties. While the British system for reporting thyroid FNA is under revision, it is now time for the Italian classification to make some adjustments (8). We are moving toward a world-standardized reporting system for thyroid FNA, allowing a more homogenous morphological assessment of the lesions. Following this trend, the performance of traditional single gene and modern multiple genes tests as well as the use of next-generation sequencing (NGS) applied to thyroid FNA can be more precisely compared and evaluated in terms of capability to detect malignancy. Immunocytochemistry (ICC) also seems to have gained a second life, with new antibodies such as GALECTIN3 and HBME1 that are now validated and commonly used in clinical routine. The introduction of antibodies like the VE1 MAB directed against the mutated $B R A F^{V 600 E}$ gene can be used as a preliminary screening before subsequent use of molecular tests. Finally, the technical evolution of core needle biopsy (CNB) and functional/molecular imaging justifies their use in the non-diagnostic category and the FNs category, respectively, with results that seem promising. The final goal is to reduce the figures of 'diagnostic' surgeries by improving the negative predictive value (NPV) of thyroid FNA.
In this review, we provide an up-to-date review of the current practice of thyroid FNA especially dedicated to the daily practice and with particular attention to the 'indeterminate' (namely follicular-patterned lesion) diagnostic category.

\section{The new Italian thyroid FNA reporting system and differences between international reporting systems}

At the beginning of 2008, the British, Italian and the Bethesda Systems for Reporting Thyroid Cytology (TBSRTC) were created and started to be used in these countries and abroad $(8,9)$. The use of standardized, consensus-based reporting categories should help make better comparisons between studies and thus allow a more comprehensive management of lesions (10). All the abovementioned classification systems include the following categories: non-diagnostic, benign, indeterminate/FN, suspicious for malignancy and malignant (Table 1). TBSRTC included an additional category, the atypia of undetermined significance/follicular lesion of undetermined significance (AUS/FLUS) whose role was to collect those lesions that were difficult to classify in an appropriate diagnostic category due to technical limitations, ambiguous morphological features or paucity of material. The recommendations resulting from the National Cancer Institute Bethesda Conference included for each reporting category, a range of risks of occurrence of a malignant tumor. TBSRTC has achieved its purpose of standardizing the reporting of thyroid cytology in US and some extra US countries, as evidenced by its high overall accuracy $(7,11)$. Concerning the European situation, except for UK and Italy, no country has proposed a reporting system so far.

Table 1 Comparison between the most frequently used thyroid cytology reporting systems.

Italy, 2014
TIR1 non-diagnostic
TIR1C non-diagnostic - cystic
TIR2 non-malignant/benign
TIR3A low-risk indeterminate lesion (LRIL)

TIR3B high-risk indeterminate lesion (HRIL)

TIR4 suspicious of malignancy

TIR5 malignant

\section{Bethesda, USA, 2008}

i) Non-diagnostic or unsatisfactory Cyst fluid only

ii) Benign

iii) Atypia of undetermined significance or follicular lesion of undetermined significance (AUS/FLUS)

iv) Follicular neoplasm or suspicious for a FN (FN/SFN)

v) Suspicious of malignancy

vi) Malignant

\begin{tabular}{l} 
UK RCPath, 2011 \\
\hline Thy1/Thy1c \\
Non-diagnostic for cytological diagnosis \\
Unsatisfactory, consistent with cyst \\
Thy2/Thy2c \\
Non-neoplastic \\
Thy3a \\
Neoplasm possible - atypia/non-diagnostic \\
Thy3f \\
Neoplasm possible - suggesting FN \\
Thy4 \\
Suspicious of malignancy \\
Thy5 \\
Malignant
\end{tabular}


Following the publication of TBSRTC, a working group of the Royal College of Pathologists (RCPath) updated the reporting system already in use since 2002 in the UK, using cytologic criteria similar to those used in TBSRTC (https://www.rcpath.org/Resources/RCPath/Migrated\% 20Resources/Documents/G/g089guidanceonthereportingofthyroidcytologyfinal.pdf, accessed 7th August 2015). Moreover, this working group decided that it might be of interest to evaluate the interobserver reproducibility of the RCPath system (12). The main difference between the UK RCPath and TBSRTC systems is that the UK RCPath classification assumes that all indeterminate and suspicious for malignancy thyroid nodules will be reviewed in a multidisciplinary clinical team meeting before a clinical decision is made. Conversely, every TBSRTC category has its own estimated risk of malignant occurrence associated with a suggested therapeutic action.

In Italy, the classification proposed in 2007 by the Italian Society for Anatomic Pathology and Cytology (SIAPEC), jointly with the Italian division of the International Academy of Pathology and the two most important societies of endocrinology, the Italian Society of Endocrinology (SIE) and the Endocrinologist Medical Association (AME), was a five-tiered reporting system (13). A recent update has been proposed by the SIAPEC in agreement with the SIE, the AME and the Italian Association of Thyroid (AIT) (Table 2) (8). It is characterized by two important additional features compared with the previous one: i) the subdivision of the nondiagnostic category in non-diagnostic (TIR1) and nondiagnostic cystic (TIR1C) and the division of the thyroid follicular proliferation category (TIR3) into two subgroups: low-risk indeterminate lesion (LRIL) and high-risk indeterminate lesion (HRIL) and ii) the inclusion of an estimated risk of malignancy for each reporting category, analogous with TBSRTC.

The suggested clinical actions have been modified accordingly. For the TIR1 category, the clinical recommendation of the 2007 system was to repeat the aspiration after 1 month in order to collect enough material to achieve a correct diagnosis. In the recent update, the Italian Working Group has included the possibility of sampling lesions repetitively non-diagnostic on FNA by using a CNB. This has been evaluated favourably by Korean and Italian studies $(14,15)$. For the TIR1C (cystic lesions), a decision is taken by the clinician based on the clinical and ultrasonographic findings. For the TIR2 (non-malignant/benign lesions), the clinical recommendation is to repeat the FNA only if there are significant clinical or ultrasonographic changes in the nodule. Patients with TIR3A - LRIL should benefit from a new aspiration within 6 months following the use of this category. The clinical management of these lesions, especially the decision regarding the surgical consultation, will be defined after the evaluation of the cytological and clinical pictures. The TIR3B - HRIL warrants a surgical resection because of the significantly high risk of malignancy at histology, which cannot be predicted by the evaluation of the cytological material alone. In follicular lesions, the frozen section examination is not recommended. For both TIR3A and TIR3B subgroups, the use of molecular techniques is regarded as an additional helpful parameter, but not sufficient by itself to select those cases that may be addressed to the surgical consultation.

The auspices of all physicians involved in the diagnosis and treatment of thyroid nodules is the creation of a global reporting system for thyroid cytology that includes the strongest parts of each existing classification in order to minimize the risk of unnecessary surgical procedures.

\section{Molecular testing}

Molecular pathology applied to thyroid FNA has become a reality and has shown interesting results for selected

Table 2 The new Italian classification system with diagnostic categories, expected risk of malignancy, and suggested actions.

\begin{tabular}{llll}
\hline Code & Diagnostic category & & Expected risk of malignancy \\
\cline { 1 - 1 } TIR1 & Non-diagnostic & Undefined \\
TIR1C & Non-diagnostic - cystic & $\begin{array}{c}\text { Low (variable on the basis of } \\
\text { clinical findings) }\end{array}$ \\
TIR2 & Non malignant & $<3 \%$ \\
TIR3A & Low-risk indeterminate lesion (LRIL) & $<10 \%$ \\
TIR3B & High-risk indeterminate lesion (HRIL) & $15-30 \%$ \\
TIR4 & Suspicious of malignancy & $60-80 \%$ \\
TIR5 & Malignant & $>95 \%$ \\
\hline
\end{tabular}

\begin{tabular}{l}
\hline Suggested actions \\
Repeat US-guided FNA after \\
at least 1 month \\
Evaluate the clinical setting \\
$\quad$ and/or repeat FNA \\
Follow-up \\
Repeat FNA/clinical follow-up \\
Surgery \\
Surgery (consider frozen section) \\
Surgery
\end{tabular}


markers (16). For this reason, the latest American Thyroid Association (ATA) guidelines recommends incorporating molecular testing in the algorithms used to manage patients with indeterminate thyroid nodules (3). A recent comment of the American Association of Clinical Endocrinologists (AACE)/ATA suggests that molecular testing may be considered in patients with nodules $>1 \mathrm{~cm}$ and/or with an indeterminate result on cytology (AUS/FLUS or FN/suspicious for a FN (SFN)) (17). Currently, molecular testing as a diagnostic aid is greatly focused on the indeterminate category.

What are the most useful molecular alterations that can be screened in a routine workup in cases with indeterminate cytology and how to apply them to thyroid FNA? The most promising ones seem to be BRAF gene mutation followed by PAX8/PPAR $\gamma$ translocation. In the presence of such alterations, the positive predictive value (PPV) for cancer is close to 100 and $80 \%$ respectively. Others markers are the RET/PTC translocations and the $R A S$-family mutations, but their PPV for cancer is lower, because these alterations are also detected in a variable percentage of non-malignant lesions. The BRAF mutation assay, due to its sensitivity for PC close to $100 \%$ also has a diagnostic value in the suspicious for malignancy category. If found positive in a case diagnosed as suspicious for PC on cytology, a frozen section analysis (usually required in such a case) can be avoided and the patient can be directly referred to the surgeon to perform a total thyroidectomy as well as a selective lymph-node resection in some cases. Moreover, BRAF mutation PPV also warrants its use in the malignant category, even if its effective value as a prognostic marker is still under debate (18). The BRAF point mutations occur in up to $75 \%$ of PC cases, but can be lower due to important geographic variability. RET/PTC translocations include numerous variants, the most frequent ones being the RET/PTC1 and RET/PTC3 translocations. Both are found more frequently in patients with a previous history of radiation exposure. RET/PTC1 translocation is more often associated with the FV of PC, while RET/PTC3 translocation is more often associated with the solid variant $(19,20,21) . R E T / P T C$ translocations have also been described in follicular adenoma (FA) and follicular oncocytic carcinoma, and are no more exclusively restricted to PC (22). The $P A X 8 / P P A R \gamma$ translocation is found in FC with frequencies up to $30 \%$, to a lesser extent in some FV of PC and rarely in FA $(23,24)$. For some authors, the presence of the $P A X 8 / P P A R \gamma$ translocation in an $\mathrm{FA}$ in which capsular and/or vascular invasion could not be demonstrated histologically warrants the use of the term 'in situ' FC, corresponding to a probable FC. Other molecular alterations, i.e. point mutation in the three $R A S$ genes $(\mathrm{H}, \mathrm{K}$, and $\mathrm{N}$ ), have also been implicated in the pathogenesis of thyroid carcinomas, but their specificity is lower than that of the previously mentioned markers, as these mutations have also been identified in quite a high percentage of FA (25). Among these mutations, codon 61 of the NRAS gene is the most frequently mutated site, and seems to be also associated with distant metastases $(26,27)$.

There are two possibilities for the practicing clinician to run molecular tests on an aspirate: outsourcing the test or using in-house facilities. In the first case, the material collected during the FNA (requires a new sampling of the nodule) is sent to a centralized laboratory for analysis. Currently, the two most well-known companies offering such services are Veracyte, San Francisco, CA, USA (AFIRMA gene classifier test) and Interpace Diagnostics, Pittsburgh, PA, USA (miRInform thyroid test - now ThyGenX) $(28,29)$. The first one is a rule-out test, in the sense that it tells which cases have a major probability to be benign. It is based on a study of the expression of mRNA from several genes in order to identify cases with a high NPV. The sensitivity, specificity, and NPV for a FN/SFN are 90,49 , and $94 \%$ respectively (28). The second test is a rulein test, in the sense that it tells which cases have a high probability to be malignant (29). It is based on a genetic study of mutations and translocations involving $B R A F$, $R A S, R E T / P T C$, and PAX8/PPARG in thyroid FNA in order to identify cases with a high PPV that can be directly addressed to surgery with a more extensive management than simple lobectomy. The sensitivity, specificity and PPV in case of indeterminate or non-diagnostic cytologic diagnosis are 48,89 , and $81 \%$ respectively (30). In follicular lesions in which a conservative approach is preferred (either because the patients do not want to be operated on or because the lesion is clinically not suspicious), one should make use of a 'rule out' test with high NPV. On the contrary, if surgery is warranted, the positive result of a 'rule in' test plays in favor of a surgical treatment. Currently, both tests are only available in the USA. On the other hand, running in-house molecular tests is more cost-effective and less restraining for the cytopathologist. For FNs, only RAS mutations and PAX8/PPAR $\gamma$ rearrangement can be detected. For FNs with atypical nuclei (suspicious for a PC), only BRAF and RAS mutations as well as RET/PTC rearrangement can be detected.

More recently, other possibilities to study FN/SFN thyroid FNA with molecular tests have been proposed, including the ThyraMIR test, by Interpace Diagnostics, a microRNA gene expression classifier that, in association 
with the ThyGenX, shows NPV of $94 \%$ and PPV of $74 \%$. Another test is the ThyroSeq v2, by CBLPATH and developed by the University of Pittsburgh Medical Center Division of Molecular and Genomic Pathology, which proposes a panel of $\sim 60$ molecular markers associated to malignancy analyzed with NGS technology. The reported sensitivity, specificity and NPV and PPV for a FN/SFN are $90,93,96$, and $83 \%$ respectively for this test $(31,32)$.

If the cytopathologist decides to use in-house available molecular tests, it is noteworthy to know that a large spectrum of cytological preparations/materials can be used. Actually, several authors have demonstrated the feasibility of molecular testing (including NGS) in routine thyroid FNA using air-dried, spray-fixed, ethanol-fixed smears, or even liquid-based cytology (LBC) material preserved in alcoholic fixative solution $(33,34,35)$.

The result of the molecular tests can be used as additional information along with clinical, ultrasonographic features and patient's health condition. From these data, a malignancy risk stratification of patients with an AUS/FLUS and FN/SFN diagnosis can be evaluated to decide whether or not surgery is indicated (36). The gain in sensitivity attributable to the application of molecular tests to FNA material is around $20 \%$, reaching $80 \%$ as opposed to $60 \%$ with cytological analysis alone (35). We should be aware that the main disadvantage of the application of molecular mutational tests to thyroid FNA remains the fact that $30-40 \%$ of thyroid cancers do not harbor known mutations.

\section{Immunocytochemistry}

In the last few years, European research groups have evidenced the potential aid of the use of ICC on FNA material, showing that it can be an accurate diagnostic and predictive tool. However, it does have a significantly lower specificity than molecular testing, especially in the category of FNs $(37,38,39,40)$. The issues in the application of ICC to cytological smears proved to be solved with the introduction of LBC which has the advantage to standardize pre-analytical conditions. This method is an alternative for collection and preparation of specimens including both cervical and FNA samples $(37,40)$. Even if there are controversies about the use of LBC in the field of thyroid cytopathology, a proven advantage of this type of processing is its reliability for the use of ancillary techniques (ICC and molecular testing) $(34,40)$. Unfortunately, none of the immunomarkers studied so far have demonstrated sufficient diagnostic accuracy to be used alone, a reason why the use of a panel made up of two
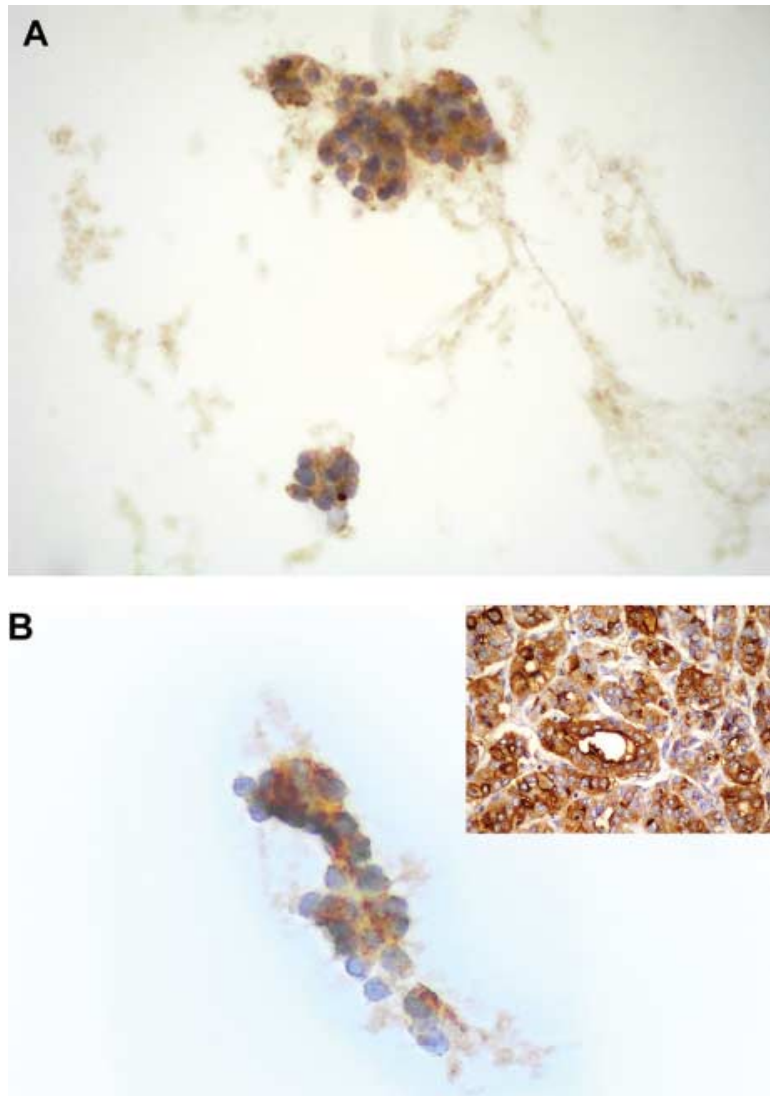

C

\section{Figure 1}

(A) GALECTIN3 expression in a follicular lesion classified Tir3B on liquid-based cytology (LBC; immunostain, 60X). (B) Membranous expression of HBME1 in a follicular lesion classified Tir3B on LBC (immunostain, $60 \times$ ). This case turned out to be a papillary thyroid carcinoma, follicular variant, with intense membranous/cytoplasmic expression of HBME1 (inset, immunostain, 60 $\times$ ). (C) VE1 expression in a lesion classified Tir4 (suspicious for carcinoma) on LBC (immunostain, 60×). 
or more immunomarkers is recommended, if not necessary. In most cases, it includes GALECTIN3 (Fig. 1A), HBME1 (Fig. 1B), and CYTOKERATIN19 $(39,41,42)$. In a recent paper, we selected 120 cases including both cytological and histological materials, and applied a panel only made up of GALECTIN3 and HBME1 (37). Even though Fadda et al. (37) assessed that, in the category of FNs (50 cases) a concordant positive panel was associated with $77 \%$ malignant histological outcome, the low specificity of ICC could only suggest but not prove a malignant histology. In the case of a thyroid lesion classified AUS/FLUS and FN/SFN, the study of the expression of GALECTIN3 and HBME1 by the follicular cells may suggest the possibility to distinguish between two subtypes of lesions: low-risk (with both GALECTIN3 and HBME1 negative) and high-risk (both GALECTIN3 and HBME1 positive) with different management and follow-up. However, the low specificity of these immunomarkers cannot guarantee a definitive diagnosis of malignancy (37).

Moreover, a series of promising immunomarkers have been studied in recent years, even if their use in routine is far from being achieved. CD44 has shown a high sensitivity in the detection of PC (97\%), although with a relatively poor specificity (43). Ki-67 proliferation index has been studied with somewhat conflicting results based on the value of nuclear expression considered as 'positive' $(44,45)$. Recently, a new interest has been given to the emerging role of a specific monoclonal antibody (VE1) directed against the mutated $B R A F^{V 600 E}$ protein (Fig. 1C) $(46,47)$. The scant literature especially in its cytological application (to date only two published series) needs to be empowered by larger and more extensive clinical series. Allegedly, a moderate $(2+)$ or strong $(3+)$ intensity of VE1 expression might be significantly correlated with the molecular $B R A F^{V 600 E}$ mutational status (46). In a recent paper, we underlined that VE1 antibody represents a feasible first-line approach to evaluate $B R A F^{V 600 E}$ mutation and might be a valid screening tool to select cases needing a molecular analysis. A statistically proven correlation has been shown between molecular testing and VE1 positivity $(P<0.0001)$ in PTC $(46)$. Thus, the use of VE1 marker might add some diagnostic and prognostic value for the management of indeterminate thyroid lesions with a positive GALECTIN3 and HBME1 immunopanel and it may represent the first step for selecting cases which perform molecular detection.

\section{Core needle biopsy}

Despite important diagnostic improvements, a nonnegligible rate of thyroid FNA is still considered inadequate $(7,48)$. These last years, several singleinstitution articles reported the use of CNB as a secondline approach in these thyroid lesions with prior inadequate or indeterminate cytology (49). Data from these papers are interesting and, more recently, this option was included in thyroid AACE/AME/European Thyroid Association (ETA) guidelines and Italian consensus for thyroid cytology $(8,48)$.

The major evidence of the value of thyroid CNB has been obtained in lesions considered inadequate (nondiagnostic) on thyroid FNA $(50,51,52,53,54)$. In this context, a relevant contribution was published by Samir et al. (50). In this study, CNB followed by a second FNA were performed in 90 nodules that had been inadequately sampled one or two times by FNA, and in up to $87 \%$ the combination of these two techniques yielded a satisfactory result. Similarly, a study by Zhang et al. (51) used both $\mathrm{CNB}$ and FNA in a large series of nodules with inadequate or suboptimal cytological outcome, and the inadequacy rate was reduced from 8.7 to $3.4 \%$ thanks to the use of both techniques. Moreover, Na et al. (54) compared CNB to a second FNA in 64 nodules inadequately sampled by a first FNA, and a significant difference was found in the number of inadequate specimens obtained by repeat FNA (28\%) vs CNB (1.6\%). Therefore, the use of CNB should be strongly considered as an alternative to diagnostic surgery in these patients.

Considering indeterminate diagnosis of FN/SFN, some papers describe the use of CNB $(14,15,54,55,56,57)$. In a study by Park et al., CNB applied to cytologically
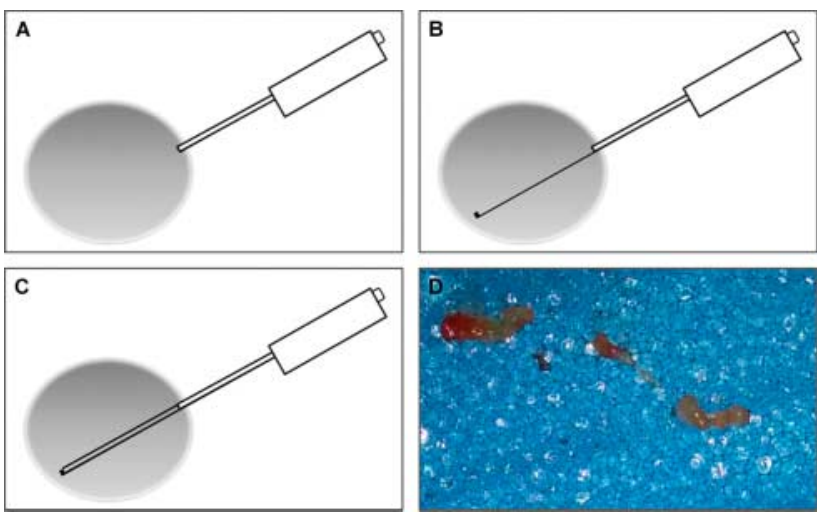

\section{Figure 2}

Schematic illustration of core needle biopsy performed with a TRU-CUT needle. (A) The needle guide reaches the border of the nodule. (B) The needle penetrates inside the nodule.

(C) Acquisition of the specimen under ultrasound guidance.

(D) Gross photograph of the fresh tissue sample before fixation. 
indeterminate nodules reached a satisfactory diagnosis in all cases, with $77.8 \%$ of cases benign, $1.8 \%$ still indeterminate and $20.3 \%$ malignant. Na et al. evaluated with CNB 161 nodules diagnosed AUS/FLUS and FN/SFN according to TBSRTC, and reached a correct diagnosis in $66.7 \%$ of benign and $67.7 \%$ of malignant tumors. A paper by Nasrollah et al. reported that a CNB sampling a nodule's capsule allowed reaching a high diagnostic accuracy, with results corroborated by other studies. Regardless of these data, CNB has not been recommended in nodules with indeterminate diagnosis (follicular lesion) due to low evidence obtained to date $(3,48)$. Even if uncommon, in case of lesions suspicious of lymphoma and malignancies metastatic to the thyroid, CNB can be very useful.

CNB sample consists of tissue fragments of $1.5 \mathrm{~cm}$ in length and with size up to $500 \mu$ (Fig. 2). These specimens constitute an optimal material for morphological examination (micro-biopsy) and extensive ancillary examinations (immunohistochemistry, molecular testing) $(58,59)$. Overall, $100 \%$ concordance has been reported between immunohistochemical evaluation of BRAF expression using the VE1 antibody and mutational analysis performed by pyrosequencing when using the same CNB material (59).

\section{Functional and molecular imaging}

The natural evolution of nodular thyroid disease includes growth of established nodules, appearance of new nodules, and development of functional autonomy over time (60). Considering a population with continuously increasing life expectancy and the frequent exposure to iodinated radiological contrast media, the risk of iodineinduced hyperthyroidism due to thyroid autonomy should not be neglected (61). Thyroid scintigraphy, with both ${ }^{99 \mathrm{~m}} \mathrm{Tc}$-pertechnetate and ${ }^{123} \mathrm{I}$ reflects the metabolic rate of thyroid cells and is the only test able to demonstrate the presence of autonomously functioning thyroid tissue (Fig. 3A). Thyroid autonomy appears as one (unifocal autonomy) or more (multifocal autonomy) hyperactive area(s) (i.e. hot nodules) while the tracer uptake is variably reduced in normal thyroid-stimulating hormone (TSH)-dependent, thyroid tissue. A timely diagnosis of thyroid autonomy allows early treatment and prevents progression toward obvious hyperthyroidism. Of even higher importance, autonomous nodules are very rarely malignant and current clinical guidelines suggest avoiding evaluating such nodules by FNA $(3,48)$.

Importantly, although a majority of nonfunctioning 'cold' nodules is benign (i.e. 90-95\%), almost all thyroid
A
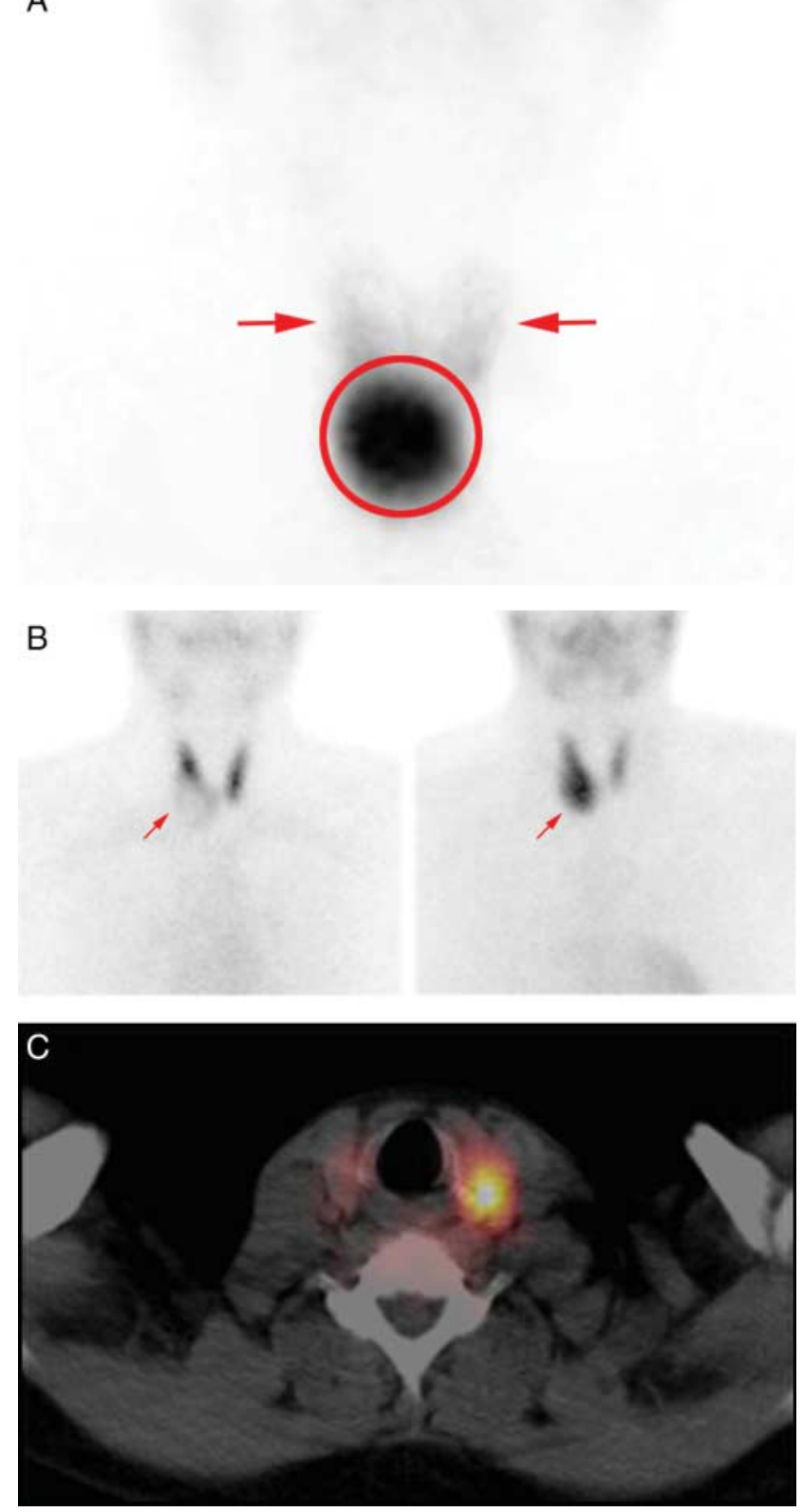

\section{Figure 3}

(A) ${ }^{99 \mathrm{~m}} \mathrm{Tc}$-pertechnetate thyroid scan: autonomous thyroid nodule (red circle) with functional suppression of the surrounding thyroid parenchyma (red arrows).

(B) ${ }^{99 \mathrm{~m}} \mathrm{Tc}$-pertechnetate (left) and ${ }^{99 \mathrm{~m}} \mathrm{Tc}$-SestaMIBI (right) double tracer thyroid scan. Left: hypofunctioning 'cold nodule' in the right thyroid lobe (arrow). Right: increased uptake of SestaMIBI in the same nodule indicating a suspicious pattern. (C) ${ }^{18} \mathrm{FDG} \mathrm{PET} / \mathrm{CT}$ (transaxial slice): hypermetabolic nodule in the left thyroid lobe indicating a suspicious pattern with a risk of malignancy of about $30 \%$. 
cancers also appear cold on thyroid scans, explaining the low specificity of cancer detection with this technique. Accordingly, a thyroid scan is usually performed when nodules occur in a background of low-to-normal TSH levels. However, the relationship between thyroid autonomy and TSH levels is dependent on the degree of iodine supply and varies widely from region to region (62). Recent AACE, AME, and ETA guidelines recognize such differences and suggest the use of thyroid scans taking into consideration the iodine supply in different geographical areas. Independent of the iodine supply status and the TSH levels, a thyroid scan with ${ }^{123} \mathrm{I}$ is suggested when evaluating nodules with indeterminate cytological readings (i.e. follicular proliferation) (48).

More recently, new radioactive tracers have become available for thyroid imaging. ${ }^{99 \mathrm{~m}} \mathrm{Tc}-\mathrm{MIBI}$ uptake within a nodule reflects its abundance of actively functioning mitochondria and therefore its oxidative burden. ${ }^{99 \mathrm{~m}}$ Tc-MIBI scan has been used by several authors to investigate thyroid nodules, in order to differentiate between benign and malignant nodules. This can be assessed either by evaluating the intensity of uptake of ${ }^{99 \mathrm{~m}}$ Tc-MIBI within a nodule and/or by demonstrating an increase in uptake within the nodule over time, in comparison with radiotracer wash-out from normal thyroid tissue (63). A recent meta-analysis, including 21 studies, demonstrated that ${ }^{99 \mathrm{~m}} \mathrm{Tc}$-MIBI scan is a sensitive diagnostic tool to predict malignancy among thyroid nodules in which malignancy is suspected on the basis of conventional diagnostic techniques (64). The pooled sensitivity, on a per lesion-based analysis, was $85 \%$ (64). In this setting, low pooled specificity (46\%) of ${ }^{99 \mathrm{~m}} \mathrm{Tc}-\mathrm{MIBI}$ scan is a major concern. However, a higher specificity can be reached when only hypofunctioning 'cold' thyroid nodules (as observed with ${ }^{99 \mathrm{~m}} \mathrm{Tc}$-pertechnetate or ${ }^{123} \mathrm{I}$ iodide scans) are studied with a ${ }^{99 \mathrm{~m}} \mathrm{Tc}$-MIBI scan. Therefore, ${ }^{99 \mathrm{~m}}$ Tc-MIBI should be performed combined with ${ }^{99 \mathrm{~m}}$ Tc-pertechnetate or ${ }^{123} \mathrm{I}$ scan in order to reduce the risk of false positive results with ${ }^{99 \mathrm{~m}} \mathrm{Tc}$-MIBI scan alone (Fig. 3B). It should be emphasized that ${ }^{99 \mathrm{~m}} \mathrm{Tc}-\mathrm{MIBI}$ scan is not specific enough to differentiate benign and malignant Hürthle cell lesions. In fact, these lesions are both characterized by a significantly increased uptake and/or retention of ${ }^{99 \mathrm{~m}} \mathrm{Tc}-\mathrm{MIBI}$, due to their peculiar molecular mechanism of ${ }^{99 \mathrm{~m}}$ Tc-MIBI washout from the cells (63). In summary, due to its low specificity, ${ }^{99 \mathrm{~m}}$ Tc-MIBI scan cannot be recommended as a first-line investigation. As a second-line investigation, it may lead to a lower rate of unnecessary surgeries. Therefore, combined FNA $/{ }^{99 \mathrm{~m}}$ Tc-MIBI scan strategies are potentially cost-effective in the management of solitary or dominant thyroid nodules (65). Interestingly, this approach recently proved to be more cost-effective than molecular AFIRMA test (66).

Finally, ${ }^{18}$ F-FDG, a positron-emitting tracer widely used to study thyroid tumors, has been evaluated to address cytologically inconclusive thyroid nodules (Fig. 3C). A recent meta-analysis regarding the diagnostic performance of ${ }^{18} \mathrm{~F}$-FDG PET or PET/CT in thyroid nodules with indeterminate FNA results reported a pooled sensitivity, specificity, PPV, NPV, and accuracy of 95, 48, 39, 96, and $60 \%$ respectively (67). In particular, a negative ${ }^{18}$ F-FDG scan in patients having a $>15 \mathrm{~mm}$ thyroid nodule with indeterminate FNA excluded thyroid cancer with a $100 \%$ NPV in a pooled population of 225 patients. In contrast, a positive ${ }^{18} \mathrm{~F}$-FDG imaging did not identify thyroid cancer, because $\sim 50 \%$ of these patients had benign thyroid nodules. However, negative ${ }^{18}$ F-FDG PET/CT was able to accurately exclude malignancy in such a challenging clinical scenario and this approach was recently proved to be highly cost-effective (68).

In summary, thyroid scintigraphy with ${ }^{99} \mathrm{~m}$ Tc-pertechnetate and ${ }^{123} \mathrm{I}$ is of great help to exclude autonomously functioning nodules from FNAC. Additionally, because of their high NPV, ${ }^{99 \mathrm{~m}} \mathrm{Tc}-\mathrm{MIBI}$ and ${ }^{18} \mathrm{~F}$-FDG can help rule out malignancy and reduce unnecessary surgeries. Their use is now supported by robust clinical data, including meta-analysis, as a second-line procedure to stratify the malignancy risk among thyroid nodules. Overall, this has been suggested to result in a cost-effective management of patients with nodular goiter, particularly when (not so infrequently) cytology is unable to provide a conclusive diagnosis.

\section{Conclusions}

In conclusion, numerous advances have been developed over the last few years to reduce the inconsistency of thyroid cytology in undetermined lesions, mostly represented by FN/SFN. Any reduction in the percentage of cases that result to be benign at definitive histology is regarded with great interest. Even if there is a low probability to reach a PPV for malignancy by cytology alone as high as in the other diagnostic categories, patients with a FNA diagnosis of FN/SFN will be candidates for additional tests aimed at better evaluating the risk of malignancy. Thus, patients will assume a more evidencebased triage between follow-up and surgery. 


\section{Declaration of interest}

The authors declare that there is no conflict of interest that could be perceived as prejudicing the impartiality of the review.

\section{Funding}

This review did not receive any specific grant from any funding agency in the public, commercial or not-for-profit sector.

\section{References}

1 Faquin WC, Bongiovanni M \& Sadow PM. Update in thyroid fine needle aspiration. Endocrine Pathology 201122 178-183. (doi:10.1007/ s12022-011-9182-7)

2 Gharib H, Papini E, Valcavi R, Baskin HJ, Crescenzi A, Dottorini ME, Duick DS, Guglielmi R, Hamilton CR Jr, Zeiger MA et al. American Association of Clinical Endocrinologists and Associazione Medici Endocrinologi medical guidelines for clinical practice for the diagnosis and management of thyroid nodules. Endocrine Practice 200612 63-102. (doi:10.4158/EP.12.2.223)

3 Cooper DS, Doherty GM, Haugen BR, Kloos RT, Lee SL, Mandel SJ, Mazzaferri EL, McIver B, Pacini F, Schlumberger M et al. Revised American Thyroid Association management guidelines for patients with thyroid nodules and differentiated thyroid cancer. Thyroid 2009 19 1167-1214. (doi:10.1089/thy.2009.0110)

4 Hambleton C \& Kandil E. Appropriate and accurate diagnosis of thyroid nodules: a review of thyroid fine-needle aspiration. International Journal of Clinical and Experimental Medicine $20136413-422$.

5 Cramer H. Fine-needle aspiration cytology of the thyroid: an appraisal. Cancer 200090 325-329. (doi:10.1002/1097-0142(20001225)90:6 $<325:: A I D-C N C R 1>3.0 . C O ; 2-U)$

6 Baloch ZW, Fleisher S, LiVolsi VA \& Gupta PK. Diagnosis of "follicular neoplasm": a gray zone in thyroid fine-needle aspiration cytology. Diagnostic Cytopathology 200226 41-44. (doi:10.1002/dc.10043)

7 Bongiovanni M, Spitale A, Faquin WC, Mazzucchelli L \& Baloch ZW. The Bethesda System for Reporting Thyroid Cytopathology: a meta-analysis. Acta Cytologica 201256 333-339. (doi:10.1159/ 000339959)

8 Nardi F, Basolo F, Crescenzi A, Fadda G, Frasoldati A, Orlandi F, Palombini L, Papini E, Zini M, Pontecorvi A et al. Italian consensus for the classification and reporting of thyroid cytology. Journal of Endocrinological Investigation 201437 593-599. (doi:10.1007/s40618-014-0062-0)

9 Cibas ES \& Ali SZ. The Bethesda System for Reporting Thyroid Cytopathology. Thyroid 200919 1159-1165. (doi:10.1089/thy. 2009.0274)

10 Lobo C, McQueen A, Beale T \& Kocjan G. The UK Royal College of Pathologists thyroid fine-needle aspiration diagnostic classification is a robust tool for the clinical management of abnormal thyroid nodules. Acta Cytologica 201155 499-506. (doi:10.1159/000333234)

11 Kholova I \& Ludvikova M. Thyroid atypia of undetermined significance or follicular lesion of undetermined significance: an indispensable Bethesda 2010 diagnostic category or waste garbage? Acta Cytologica 201458 319-329. (doi:10.1159/000366498)

12 Kocjan G, Chandra A, Cross PA, Giles T, Johnson SJ, Stephenson TJ, Roughton $\mathrm{M} \&$ Poller DN. The interobserver reproducibility of thyroid fine-needle aspiration using the UK Royal College of Pathologists' classification system. American Journal of Clinical Pathology 2011135 852-859. (doi:10.1309/AJCPZ33MVMGZKEWU)

13 Fadda G, Basolo F, Bondi A, Bussolati G, Crescenzi A, Nappi O, Nardi F, Papotti M, Taddei G \& Palombini L. Cytological classification of thyroid nodules. Proposal of the SIAPEC-IAP Italian Consensus Working Group. Pathologica 2010102 405-408.
14 Park KT, Ahn SH, Mo JH, Park YJ, Park do J, Choi SI \& Park SY. Role of core needle biopsy and ultrasonographic finding in management of indeterminate thyroid nodules. Head \& Neck 201133 160-165. (doi:10.1002/hed.21414)

15 Nasrollah N, Trimboli P, Guidobaldi L, Cicciarella Modica DD, Ventura C, Ramacciato G, Taccogna S, Romanelli F, Valabrega S \& Crescenzi A. Thin core biopsy should help to discriminate thyroid nodules cytologically classified as indeterminate. A new sampling technique. Endocrine 201343 659-665. (doi:10.1007/ s12020-012-9811-z)

16 Xing M, Haugen BR \& Schlumberger M. Progress in molecular-based management of differentiated thyroid cancer. Lancet $2013 \mathbf{3 8 1}$ 1058-1069. (doi:10.1016/S0140-6736(13)60109-9)

17 Bernet V, Hupart KH, Parangi S \& Woeber KA. AACE/ACE disease state commentary: molecular diagnostic testing of thyroid nodules with indeterminate cytopathology. Endocrine Practice 201420 360-363. (doi:10.4158/EP14066.PS)

18 Gandolfi G, Sancisi V, Piana S \& Ciarrocchi A. Time to re-consider the meaning of BRAF V600E mutation in papillary thyroid carcinoma. International Journal of Cancer 2014137 1001-1011. (doi:10.1002/ ijc.28976)

19 Nikiforov YE, Rowland JM, Bove KE, Monforte-Munoz H \& Fagin JA. Distinct pattern of ret oncogene rearrangements in morphological variants of radiation-induced and sporadic thyroid papillary carcinomas in children. Cancer Research 199757 1690-1694.

20 Rabes HM, Demidchik EP, Sidorow JD, Lengfelder E, Beimfohr C, Hoelzel D \& Klugbauer S. Pattern of radiation-induced RET and NTRK1 rearrangements in 191 post-chernobyl papillary thyroid carcinomas: biological, phenotypic, and clinical implications. Clinical Cancer Research 20006 1093-1103.

21 Bounacer A, Wicker R, Caillou B, Cailleux AF, Sarasin A, Schlumberger $M$ \& Suarez HG. High prevalence of activating ret proto-oncogene rearrangements, in thyroid tumors from patients who had received external radiation. Oncogene 199715 1263-1273. (doi:10.1038/sj.onc.1200206)

22 de Vries MM, Celestino R, Castro P, Eloy C, Maximo V, van der Wal JE, Plukker JT, Links TP, Hofstra RM, Sobrinho-Simoes $\mathrm{M}$ et al. RET/PTC rearrangement is prevalent in follicular Hurthle cell carcinomas. Histopathology 201261 833-843. (doi:10.1111/j.1365-2559.2012. 04276.x)

23 Raman P \& Koenig RJ. Pax-8-PPAR- $\gamma$ fusion protein in thyroid carcinoma. Nature Reviews. Endocrinology 201410 616-623. (doi:10.1038/nrendo.2014.115)

24 Ferraz C, Rehfeld C, Krogdahl A, Precht Jensen EM, Bösenberg E, Narz F, Hegedüs L, Paschke R \& Eszlinger M. Detection of PAX8/PPARG and $\mathrm{RET} / \mathrm{PTC}$ rearrangements is feasible in routine air-dried fine needle aspiration smears. Thyroid 201222 1025-1030. (doi:10.1089/ thy.2011.0391)

25 Howell GM, Hodak SP \& Yip L. RAS mutations in thyroid cancer. Oncologist 201318 926-932. (doi:10.1634/theoncologist.2013-0072)

26 Schulten HJ, Salama S, Al-Ahmadi A, Al-Mansouri Z, Mirza Z, Al-Ghamdi K, Al-Hamour OA, Huwait E, Gari M, Al-Qahtani MH et al. Comprehensive survey of HRAS, KRAS, and NRAS mutations in proliferative thyroid lesions from an ethnically diverse population. Anticancer Research 201333 4779-4784.

27 Jang EK, Song DE, Sim SY, Kwon H, Choi YM, Jeon MJ, Han JM, Kim WG, Kim TY, Shong YK et al. NRAS codon 61 mutation is associated with distant metastasis in patients with follicular thyroid carcinoma. Thyroid 201424 1275-1281. (doi:10.1089/thy.2014.0053)

28 Alexander EK, Kennedy GC, Baloch ZW, Cibas ES, Chudova D, Diggans J, Friedman L, Kloos RT, LiVolsi VA, Mandel SJ et al. Preoperative diagnosis of benign thyroid nodules with indeterminate cytology. New England Journal of Medicine 2012367 705-715. (doi:10.1056/NEJMoa1203208)

29 Nikiforov YE, Steward DL, Robinson-Smith TM, Haugen BR, Klopper JP, Zhu Z, Fagin JA, Falciglia M, Weber K \& Nikiforova MN. Molecular 
testing for mutations in improving the fine-needle aspiration diagnosis of thyroid nodules. Journal of Clinical Endocrinology and Metabolism 2009 94 2092-2098. (doi:10.1210/jc.2009-0247)

30 Beaudenon-Huibregtse S, Alexander EK, Guttler RB, Hershman JM, Babu V, Blevins TC, Moore P, Andruss B \& Labourier E. Centralized molecular testing for oncogenic gene mutations complements the local cytopathologic diagnosis of thyroid nodules. Thyroid $2014 \mathbf{2 4}$ 1479-1487. (doi:10.1089/thy.2013.0640)

31 Emmanuel L, Sylvie B, Dennis W \& Thomas JG. Multicategorical testing for miRNA, mRNA and DNA on fine needle aspiration improves the preoperative diagnosis of thyroid nodules with indeterminate cytology. Abstract 18782 of the 97th Annual Meeting \& Expo of the Endocrine Society, March 5-8. San Diego, CA, 2015.

32 Nikiforov YE, Carty SE, Chiosea SI, Coyne C, Duvvuri U, Ferris RL, Gooding WE, Hodak SP, LeBeau SO, Ohori NP et al. Highly accurate diagnosis of cancer in thyroid nodules with follicular neoplasm/ suspicious for a follicular neoplasm cytology by ThyroSeq v2 next-generation sequencing assay. Cancer $20141203627-3634$. (doi:10.1002/cncr.29038)

33 Cochand-Priollet B. Thyroid cytopathology: how far can we go? Cytopathology 201425 143-145. (doi:10.1111/cyt.12160)

34 Bongiovanni M, Molinari F, Eszlinger M, Paschke R, Barizzi J, Merlo E, Giovanella L, Fasolini F, Cattaneo F, Ramelli F et al. Laser capture microdissection is a valuable tool in the preoperative molecular screening of follicular lesions of the thyroid: an institutional experience. Cytopathology 201426 288-296. (doi:10.1111/cyt.12226)

35 Eszlinger M, Piana S, Moll A, Bosenberg E, Bisagni A, Ciarrocchi A, Ragazzi M \& Paschke R. Molecular testing of thyroid fine-needle aspirations improves presurgical diagnosis and supports the histologic identification of minimally invasive follicular thyroid carcinomas. Thyroid 201525 401-409. (doi:10.1089/thy.2014.0362)

36 Ferraz C, Eszlinger M \& Paschke R. Current state and future perspective of molecular diagnosis of fine-needle aspiration biopsy of thyroid nodules. Journal of Clinical Endocrinology and Metabolism 201196 2016-2026. (doi:10.1210/jc.2010-2567)

37 Fadda G, Rossi ED, Raffaelli M, Pontecorvi A, Sioletic S, Morassi F, Lombardi CP, Zannoni GF \& Rindi G. Follicular thyroid neoplasms can be classified as low- and high-risk according to HBME-1 and Galectin-3 expression on liquid-based fine-needle cytology. European Journal of Endocrinology 2011165 447-453. (doi:10.1530/EJE-11-0181)

38 Lacoste-Collin L, d'Aure D, Berard E, Rouquette I, Delisle MB \& Courtade-Saidi M. Improvement of the cytological diagnostic accuracy of follicular thyroid lesions by the use of the Ki-67 proliferative index in addition to cytokeratin-19 and HBME-1 immunomarkers: a study of 61 cases of liquid-based FNA cytology with histological controls. Cytopathology 201425 160-169. (doi:10.1111/cyt.12128)

39 Cochand-Priollet B, Dahan H, Laloi-Michelin M, Polivka M, Saada M, Herman P, Guillausseau PJ, Hamzi L, Pote N, Sarfati E et al. Immunocytochemistry with cytokeratin 19 and anti-human mesothelial cell antibody (HBME1) increases the diagnostic accuracy of thyroid fine-needle aspirations: preliminary report of 150 liquid-based fine-needle aspirations with histological control. Thyroid 201121 1067-1073. (doi:10.1089/thy.2011.0014)

40 Rossi ED, Fadda G \& Schmitt F. The nightmare of indeterminate follicular proliferations: when liquid-based cytology and ancillary techniques are not a moon landing but a realistic plan. Acta Cytologica 201458 543-551. (doi:10.1159/000363439)

41 Rodrigues HG, de Pontes AA \& Adan LF. Use of molecular markers in samples obtained from preoperative aspiration of thyroid. Endocrine Journal 201259 417-424. (doi:10.1507/endocrj.EJ11-0410)

42 Bartolazzi A, Orlandi F, Saggiorato E, Volante M, Arecco F, Rossetto R, Palestini N, Ghigo E, Papotti M, Bussolati G et al. Galectin-3-expression analysis in the surgical selection of follicular thyroid nodules with indeterminate fine-needle aspiration cytology: a prospective multicentre study. Lancet. Oncology 20089 543-549. (doi:10.1016/ S1470-2045(08)70132-3)
43 Das DK, Al-Waheeb SK, George SS, Haji BI \& Mallik MK. Contribution of immunocytochemical stainings for galectin-3, CD44, and HBME1 to fine-needle aspiration cytology diagnosis of papillary thyroid carcinoma. Diagnostic Cytopathology 201442 498-505. (doi:10.1002/ dc.23062)

44 Pisani T, Pantellini F, Centanni M, Vecchione A \& Giovagnoli MR. Immunocytochemical expression of Ki67 and laminin in Hurthle cell adenomas and carcinomas. Anticancer Research 200323 3323-3326.

45 Sofiadis A, Tani E, Foukakis T, Kjellman P, Skoog L, Hoog A, Wallin G, Zedenius J \& Larsson C. Diagnostic and prognostic potential of MIB-1 proliferation index in thyroid fine needle aspiration biopsy. International Journal of Oncology 200935 369-374.

46 Rossi ED, Martini M, Capodimonti S, Cenci T, Straccia P, Angrisani B, Ricci C, Lanza P, Lombardi CP, Pontecorvi A et al. Analysis of immunocytochemical and molecular BRAF expression in thyroid carcinomas: a cytohistologic institutional experience. Cancer Cytopathology 2014122 527-535. (doi:10.1002/cncy.21416)

47 Zimmermann AK, Camenisch U, Rechsteiner MP, Bode-Lesniewska B \& Rossle M. Value of immunohistochemistry in the detection of BRAF(V600E) mutations in fine-needle aspiration biopsies of papillary thyroid carcinoma. Cancer Cytopathology 2014122 48-58. (doi:10.1002/cncy.21352)

48 Gharib H, Papini E, Paschke R, Duick DS, Valcavi R, Hegedus L \& Vitti P. American Association of Clinical Endocrinologists, Associazione Medici Endocrinologi, and European Thyroid Association Medical guidelines for clinical practice for the diagnosis and management of thyroid nodules: executive summary of recommendations. Endocrine Practice 201016 468-475. (doi:10.4158/EP.16.3.468)

49 Trimboli P \& Crescenzi A. Thyroid core needle biopsy: taking stock of the situation. Endocrine 201448 779-785. (doi:10.1007/s12020014-0382-z)

50 Samir AE, Vij A, Seale MK, Desai G, Halpern E, Faquin WC, Parangi S, Hahn PF \& Daniels GH. Ultrasound-guided percutaneous thyroid nodule core biopsy: clinical utility in patients with prior nondiagnostic fine-needle aspirate. Thyroid 201222 461-467. (doi:10.1089/ thy.2011.0061)

51 Zhang S, Ivanovic M, Nemcek AA Jr, Defrias DV, Lucas E \& Nayar R. Thin core needle biopsy crush preparations in conjunction with fine-needle aspiration for the evaluation of thyroid nodules: a complementary approach. Cancer $2008 \mathbf{1 1 4}$ 512-518. (doi:10.1002/ cncr.23982)

52 Lee SH, Kim MH, Bae JS, Lim DJ, Jung SL \& Jung CK. Clinical outcomes in patients with non-diagnostic thyroid fine needle aspiration cytology: usefulness of the thyroid core needle biopsy. Annals of Surgical Oncology 201421 1870-1877. (doi:10.1245/s10434-013-3365-z)

53 Yeon JS, Baek JH, Lim HK, Ha EJ, Kim JK, Song DE, Kim TY \& Lee JH. Thyroid nodules with initially nondiagnostic cytologic results: the role of core-needle biopsy. Radiology 2013268 274-280. (doi:10.1148/ radiol.13122247)

54 Na DG, Kim JH, Sung JY, Baek JH, Jung KC, Lee H \& Yoo H. Core-needle biopsy is more useful than repeat fine-needle aspiration in thyroid nodules read as nondiagnostic or atypia of undetermined significance by the Bethesda System for Reporting Thyroid Cytopathology. Thyroid 201222 468-475. (doi:10.1089/thy.2011.0185)

55 Hahn SY, Shin JH, Han BK, Ko EY \& Ko ES. Ultrasonography-guided core needle biopsy for the thyroid nodule: does the procedure hold any benefit for the diagnosis when fine-needle aspiration cytology analysis shows inconclusive results? British Journal of Radiology 201386 20130007. (doi:10.1259/bjr.20130007)

56 Min HS, Kim JH, Ryoo I, Jung SL \& Jung CK. The role of core needle biopsy in the preoperative diagnosis of follicular neoplasm of the thyroid. Apmis 2014122 993-1000. (doi:10.1111/apm.12244)

57 Choi YJ, Baek JH, Ha EJ, Lim HK, Lee JH, Kim JK, Song DE, Shong YK \& Hong SJ. Differences in risk of malignancy and management recommendations in subcategories of thyroid nodules with atypia of undetermined significance or follicular lesion of undetermined 
significance: the role of ultrasound-guided core-needle biopsy. Thyroid 201424 494-501. (doi:10.1089/thy.2012.0635)

58 Renshaw AA \& Pinnar N. Comparison of thyroid fine-needle aspiration and core needle biopsy. American Journal of Clinical Pathology $2007 \mathbf{1 2 8}$ 370-374. (doi:10.1309/07TL3V58337TXHMC)

59 Crescenzi A, Guidobaldi L, Nasrollah N, Taccogna S, Cicciarella Modica DD, Turrini L, Nigri G, Romanelli F, Valabrega S, Giovanella L et al. Immunohistochemistry for BRAF(V600E) antibody VE1 performed in core needle biopsy samples identifies mutated papillary thyroid cancers. Hormone and Metabolic Research 201446 370-374. (doi:10.1055/s-0034-1368700)

60 Krohn K \& Paschke R. Clinical review 133: Progress in understanding the etiology of thyroid autonomy. Journal of Clinical Endocrinology and Metabolism 200186 3336-3345.

61 Meller J \& Becker W. The continuing importance of thyroid scintigraphy in the era of high-resolution ultrasound. European Journal of Nuclear Medicine and Molecular Imaging 200229 (Suppl 2) S425-S438. (doi:10.1007/s00259-002-0811-8)

62 van de Ven AC, Netea-Maier RT, Ross HA, van Herwaarden TA, Holewijn S, de Graaf J, Kiemeney BL, van Tienoven D, Wetzels JF, Smit JW et al. Longitudinal trends in thyroid function in relation to iodine intake: ongoing changes of thyroid function despite adequate current iodine status. European Journal of Endocrinology 2014170 49-54. (doi:10.1530/EJE-13-0589)

63 Saggiorato E, Angusti T, Rosas R, Martinese M, Finessi M, Arecco F, Trevisiol E, Bergero N, Puligheddu B, Volante M et al. ${ }^{99 \mathrm{~m}} \mathrm{Tc}-\mathrm{MIBI}$ Imaging in the presurgical characterization of thyroid follicular neoplasms: relationship to multidrug resistance protein expression. Journal of Nuclear Medicine 200950 1785-1793. (doi:10.2967/jnumed. 109.064980)
64 Treglia G, Caldarella C, Saggiorato E, Ceriani L, Orlandi F, Salvatori M \& Giovanella L. Diagnostic performance of $(99 \mathrm{~m})$ Tc-MIBI scan in predicting the malignancy of thyroid nodules: a meta-analysis. Endocrine 201344 70-78. (doi:10.1007/s12020-013-9932-z)

65 Hurtado-Lopez LM, Arellano-Montano S, Torres-Acosta EM, Zaldivar-Ramirez FR, Duarte-Torres RM, Alonso-De-Ruiz P, Martinez-Duncker I \& Martinez-Duncker C. Combined use of fine-needle aspiration biopsy, MIBI scans and frozen section biopsy offers the best diagnostic accuracy in the assessment of the hypofunctioning solitary thyroid nodule. European Journal of Nuclear Medicine and Molecular Imaging 200431 1273-1279. (doi:10.1007/ s00259-004-1544-7)

66 Heinzel A, Muller D, Behrendt FF, Giovanella L, Mottaghy FM \& Verburg FA. Thyroid nodules with indeterminate cytology: molecular imaging with (9)(9)mTc-methoxyisobutylisonitrile (MIBI) is more costeffective than the Afirma gene expression classifier. European Journal of Nuclear Medicine and Molecular Imaging 201441 1497-1500. (doi:10.1007/s00259-014-2760-4)

67 Vriens D, de Wilt JH, van der Wilt GJ, Netea-Maier RT, Oyen WJ \& de Geus-Oei LF. The role of $\left[{ }^{18} \mathrm{~F}\right]$-2-fluoro-2-deoxy-D-glucosepositron emission tomography in thyroid nodules with indeterminate fine-needle aspiration biopsy: systematic review and meta-analysis of the literature. Cancer 2011117 4582-4594. (doi:10.1002/cncr.26085)

68 Vriens D, Adang EM, Netea-Maier RT, Smit JW, de Wilt JH, Oyen WJ \& de Geus-Oei LF. Cost-effectiveness of FDG-PET/CT for cytologically indeterminate thyroid nodules: a decision analytic approach. Journal of Clinical Endocrinology and Metabolism 201499 3263-3274. (doi:10.1210/ jc.2013-3483)

Received 11 August 2015

Revised version received 2 October 2015

Accepted 7 October 2015 